\title{
Protective effect of ISO-1 against advanced glycation end product aggravation of PC12 cell injury induced by $A \beta_{1-40}$
}

\author{
MING YU ${ }^{1,2}$, DEMEI ZANG $^{2}$, YUHAO XU ${ }^{1}$, JIE MENG $^{2}$ and SHENGNAN QIAN ${ }^{2}$ \\ ${ }^{1}$ Department of Neurology, Affiliated Hospital of Jiangsu University; \\ ${ }^{2}$ School of Medicine, Jiangsu University, Zhenjiang, Jiangsu 212000, P.R. China
}

Received January 31, 2019; Accepted May 24, 2019

DOI: $10.3892 / \mathrm{mmr} .2019 .10483$

\begin{abstract}
Advanced glycation end products (AGEs) are important pathogenic substances involved in diabetes mellitus (DM) and its complications. AGEs also serve important roles in promoting the development of Alzheimer's disease (AD). Macrophage migration inhibitory factor (MIF), an inflammatory stimulant and a pathogenic factor involved in DM, was previously reported to be present at increased levels in the cerebrospinal fluid of patients with $\mathrm{AD}$ and mild cognitive impairment compared with age-matched healthy controls. By investigating the association between AGEs and MIF, and the effects of neuroinflammation on $\mathrm{AD}$, the present study aimed to increase understanding of the specific molecular mechanisms involved in the pathogenesis of $\mathrm{DM}$ and $\mathrm{AD}$, and the connection between these diseases. PC12 cells were cultured in vitro; the levels of MIF mRNA and protein were determined using reverse transcription-quantitative (RT-q)PCR and western blot analyses. The optimal concentrations of AGEs and amyloid $\beta$ 1-40 $\left(\mathrm{A} \beta_{1-40}\right)$ were also determined in the cell model of AD using Cell Counting Kit-8 and MTT assays. Cell numbers and morphological changes were observed following the treatment of $\mathrm{A} \beta_{1-40}$-stimulated PC12 cells with AGEs and the MIF inhibitor (S,R)-3-(4-hydroxyphenyl)-4,5-dihydro-5-isoxazole acetic acid methyl ester (ISO-1). The mRNA expression levels of interleukin (IL)-1 $\beta$, IL-6, tumor necrosis factor- $\alpha$ (TNF- $\alpha$ ) and MIF were determined via RT-qPCR analysis. The results showed that the levels of MIF mRNA and protein were significantly increased in cells treated with AGEs compared
\end{abstract}

Correspondence to: Dr Ming Yu, Department of Neurology, Affiliated Hospital of Jiangsu University, 438 Jiefang Road, Jingkou, Zhenjiang, Jiangsu 212000, P.R. China

E-mail: yuming7251@163.com

Miss Demei Zang, School of Medicine, Jiangsu University, 301 Xuefu Road, Jingkou, Zhenjiang, Jiangsu 212000, P.R. China E-mail: demeiz0709@163.com

Key words: amyloid $\beta 1-40$, Alzheimer's disease, $\mathrm{PC} 12$ cell, advanced glycation end products, macrophage migration inhibitory factor, diabetes mellitus, (S,R)-3-(4-hydroxyphenyl)-4,5-dihydro-5-isoxazole acetic acid methyl ester with the control group. In the AD model group, the inhibition of PC12 cell growth was significantly increased, and the mRNA expression levels of IL-1 $\beta$, IL- 6 , TNF- $\alpha$ and MIF were also increased. Compared with treatment with AGEs alone, the combination of AGEs treatment with ISO-1 significantly improved the survival rate and resulted in the reduced expression of inflammatory mediators in the AD cell model. Thus, ISO-1 reduced AGEs-mediated damage in the AD cell model. This may be a consequence of AGEs-mediated MIF expression promoting neuritis in the AD cell model, whereas ISO-1 decreased the expression of neuroinflammatory mediators.

\section{Introduction}

Alzheimer's disease (AD) is the most common neurodegenerative disorder of the central nervous system. Worldwide, $>46.8$ million patients have been diagnosed with AD, with $50 \%$ of those patients $>85$ years of age. The number of individuals with AD is expected to double by 2030 (1-3). Previous studies have reported a correlation between diabetes mellitus (DM) and the risk of developing AD (4,5). Certain scholars have even suggested that AD should be considered as a third type of DM (6-9).

Advanced glycation end products (AGEs) affect the functions of normal tissues through different pathways and play important roles in the occurrence and development of various diseases, including diabetic complications, osteoporosis, AD, tumorigenesis, aging and cardiovascular disease (10-13). AGEs can induce apoptosis in neurons, leading to the early onset of AD (14). Additionally, substantial quantities of carboxymethyllysine, pyrraline and pentosidine have been detected in the senile plaques and neurofibrillary tangles (NFTs) of patients with AD; these AGEs may promote the development of AD by affecting the metabolism of amyloid $\beta(A \beta)(15)$.

Macrophage migration inhibitory factor (MIF) is a cytokine involved in the occurrence of various inflammatory and immune diseases $(16,17)$. The inhibitor of MIF, (S,R)-3-(4-hydroxyphenyl)-4,5-dihydro-5-isoxazole acetic acid methyl ester (ISO-1), can significantly inhibit the activity of MIF and affect its pathophysiological functions (18). MIF activity is one of the risk factors for type I diabetes and type II diabetes (T2D) $(17,19)$. A previous clinical study by Bacher et al (20) reported significantly increased MIF levels in the cerebrospinal fluid of patients with AD and mild cognitive 
impairment (MCI) compared with controls of the same age. Oyama et al (21) reported that MIF bound to $A \beta$ in the brains of patients with $A D$, and thus, the toxicity of $A \beta$ was directly attributed to the upregulation of MIF expression. MIF deficiency was also reported to attenuate the hyperphosphorylation of tau proteins (22).

Previous studies have identified a close link between DM and AD (4,5); however, the exact molecular link between these two diseases remains unclear. AGEs promote the deposition of $\mathrm{A} \beta$ and the hyperphosphorylation of tau protein $(14,15)$. Whether MIF also serves a role in the AGEs-induced development of AD requires further investigation. The present study investigated the neuroinflammatory mechanisms underlying the pathogenesis of AD and assessed the effect of the pathogenic factor MIF on AD. It was hypothesized that AGEs would affect the levels of neuroinflammation observed in AD by inducing MIF expression, and that the levels of neuroinflammation could be reduced using ISO-1.

\section{Materials and methods}

Cell culture and treatment. PC12 cells were purchased from the Type Culture Collection of the Chinese Academy of Sciences. PC12 cells were cultured in DMEM (HyClone; GE Healthcare Life Sciences) supplemented with 10\% FBS (Zhejiang Tianhang Biotechnology Co., Ltd.) at $37^{\circ} \mathrm{C}$ in a humidified atmosphere of $5 \% \mathrm{CO}_{2} / 95 \%$ air. PC12 cells in the logarithmic phase of growth were plated in 6-well plates at the density of $5 \times 10^{5} / \mathrm{ml}$ and divided into three treatment groups: A blank control group, a BSA $(300 \mu \mathrm{g} / \mathrm{ml}$; Beijing ComWin Biotech Co., Ltd.) control group and an AGEs (Biorbyt, Ltd.) group. The AGEs group were treated with different concentrations $(100,200$ or $300 \mu \mathrm{g} / \mathrm{ml})$ of AGEs for $24 \mathrm{~h}$ at $37^{\circ} \mathrm{C}$, and then subsequent assays were performed. As AGEs were prepared in a non-enzymatic glycosylation reaction using BSA as a substrate, BSA (300 $\mu \mathrm{g} / \mathrm{ml})$ was also used as a control.

Reverse transcription-quantitative $(R T-q) P C R$. Total RNA was extracted from cells using TRIzol ${ }^{\circledR}$ reagent (Invitrogen; Thermo Fisher Scientific, Inc.) following the aforementioned treatments, according to the manufacturer's protocol. For mRNA analysis, cDNAs were synthesized using a TIANScript First Strand cDNA Synthesis kit (Tiangen Biotech Co., Ltd.), according to the manufacturer's protocol. The temperature protocol for the reverse transcription reaction was $37^{\circ} \mathrm{C}$ for 60 min. qPCR was performed using a SuperReal PreMix Color (SYBR-Green; Tiangen Biotech Co., Ltd.) in an Mx3000P system (Agilent Technologies, Inc.). The cycling conditions included a pre-denaturation step at $95^{\circ} \mathrm{C}$ for $15 \mathrm{~min}$, followed by 40 cycles of denaturation at $95^{\circ} \mathrm{C}$ for $10 \mathrm{sec}$, annealing at $55^{\circ} \mathrm{C}$ for $20 \mathrm{sec}$ and extension at $72^{\circ} \mathrm{C}$ for $32 \mathrm{sec}$. The primer sequences used in this study are presented in Table I. Quantification cycle $(\mathrm{Cq})$ values for the target genes and the internal control gene, GAPDH, were measured. The expression levels of each mRNA were determined from three independent experiments, and the fold change was calculated using the $2^{-\Delta \Delta \mathrm{Cq}}$ method (23).

Western blot analysis. Protein levels in PC12 cells were determined after treatment using western blot analysis. Cells were
Table I. Oligonucleotide primer sets used for reverse transcription-quantitative PCR.

\begin{tabular}{llc}
\hline Name & \multicolumn{1}{c}{ Sequence (5'-3') } & $\begin{array}{c}\text { Length } \\
(\mathrm{bp})\end{array}$ \\
\hline MIF & F: TACGACATGAACGCAGCCAACG & 22 \\
& R: GAACAGCGGTGCAGGTAAGTGAG & 23 \\
IL-1 $\beta$ & F: ATCTCACAGCAGCATCTCGACAAG & 24 \\
& R: CACACTAGCAGGTCGTCATCATCC & 24 \\
IL-6 & F: ATGATGAGAAACGAGCCAATTG & 22 \\
& R: GCTTTGGCTTCTTTCTTACGAG & 22 \\
TNF- $\alpha$ & F: TTGGGTTATGCCAAAGATGTTG & 22 \\
& R: GCTGTGTACGGCTTATTTTCAA & 22 \\
GAPDH & F: ACGGCAAGTTCAACGGCACAG & 21 \\
& R: CGACATACTCAGCACCAGCATCAC & 24 \\
\hline
\end{tabular}

F, forward; R, reverse; MIF, macrophage migration inhibitory factor; $\mathrm{IL}$, interleukin; TNF- $\alpha$, tumor necrosis factor- $\alpha$.

lysed with RIPA lysis buffer (Sigma-Aldrich; Merck KGaA) containing a protease inhibitor cocktail (Sigma-Aldrich; Merck KGaA). Samples were incubated on ice for $30 \mathrm{~min}$ and then centrifuged at $16,000 \mathrm{x}$ g for $15 \mathrm{~min}$ at $4^{\circ} \mathrm{C}$. The supernatant was removed and the protein concentration was determined using the bicinchoninic acid method. Total protein $(50 \mu \mathrm{g})$ was separated on 12\% SDS-PAGE gels and transferred to PVDF membranes. Membranes were blocked with 5\% dried skimmed milk/TBS $0.5 \%$ Tween-20 (TBST) for $1 \mathrm{~h}$ at room temperature. Membranes were incubated overnight at $4^{\circ} \mathrm{C}$ with a monoclonal rabbit anti-MIF antibody (1:100; cat. no. ab172730; Abcam) or anti-GAPDH antibody (1:1,000; cat. no. CW0101S; Beijing ComWin Biotech Co., Ltd.), and then washed three times with TBST for 10 min each. Subsequently, horseradish peroxidase-conjugated goat anti-rabbit immunoglobulin $\mathrm{G}$ (1:10,000; cat. no. D110058; BBI Life Sciences Corporation) secondary antibody was incubated with the membranes for $1 \mathrm{~h}$ at room temperature, which were then washed three times with TBST for $10 \mathrm{~min}$ each. The bands were visualized with an ECL reagent (Tanon Science and Technology Co., Ltd.) and detected with the Tanon Imaging System (Tanon Science and Technology Co., Ltd.). The relative intensity of the protein bands was quantified using Image-Pro Plus 6.0 software (Media Cybernetics, Inc.). Experiments were repeated three times.

Screening for the optimum concentration of AGEs and $A \beta_{1-40}$ in the AD cell model. PC12 cells were plated in 96-well plates at the density of $5 \times 10^{5} / \mathrm{ml}$, and the cells were exposed to various concentrations of AGEs (100-400 $\mu \mathrm{g} / \mathrm{ml})$ at $37^{\circ} \mathrm{C}$ for $24 \mathrm{~h}$, with 5 replicates/group; equivalent concentrations were applied to the BSA control group. All groups were treated with $10 \mu \mathrm{l}$ of Cell Counting Kit-8 (CCK-8) reagent (Dojindo Molecular Technologies, Inc.) and incubated for $1-4 \mathrm{~h}$ at $37^{\circ} \mathrm{C}$ before the absorbance was measured at $450 \mathrm{~nm}$ using a microplate reader to detect surviving cells.

$\mathrm{A} \beta_{1-40}$ (Shanghai Aladdin Biochemical Technology Co., Ltd.) was dissolved in sterile PBS and incubated at $37^{\circ} \mathrm{C}$ for 7 days to induce aggregation prior to treatment. PC12 cells 
were plated in 96-well plates at the density of $5 \times 10^{5} / \mathrm{ml}$. The blank control group was treated with $100 \mu \mathrm{l}$ of fresh culture medium and the AD model groups were incubated with $100 \mu \mathrm{l}$ of medium containing different concentrations $(10-40 \mu \mathrm{g} / \mathrm{ml})$ of $\mathrm{A} \beta_{1-40}$ at $37^{\circ} \mathrm{C}$ for $2,6,12$ or $24 \mathrm{~h}$, with 3 replicates/group (24). All groups were treated with $5 \mathrm{mg} / \mathrm{ml}$ MTT solution $10 \mu \mathrm{l}$ at $37^{\circ} \mathrm{C}$ for $4 \mathrm{~h}$, the medium was then discarded and $100 \mu \mathrm{l}$ dimethyl sulfoxide was added to each well to dissolve the formazan crystal product. The absorbance was measured at $570 \mathrm{~nm}$ using a microplate reader.

Observation of cell number and morphology under an inverted microscope, and detection of cell activity using the MTT method. PC12 cells were plated in 12-well plates at the density of $5 \times 10^{5} / \mathrm{ml}$. The cells were exposed to $300 \mu \mathrm{g} / \mathrm{ml}$ AGEs at $37^{\circ} \mathrm{C}$ for $24 \mathrm{~h}$ and then treated with $20 \mu \mathrm{g} / \mathrm{ml} \mathrm{A} \beta_{1-40}$ at $37^{\circ} \mathrm{C}$ for $12 \mathrm{~h}$. To assess the effect of AGEs on the expression of inflammatory mediators through MIF and to determine the effect of ISO-1, cells were pre-treated with $7 \mu \mathrm{M}$ ISO-1 (MedChemExpress LLC) at $37^{\circ} \mathrm{C}$ for $1 \mathrm{~h}$. The blank control group and the $A \beta_{1-40}$ model group were used as control groups, with 3 replicates/group. Following treatment, the number and morphology of the cells were observed under an inverted microscope (magnification x100). Each sample was analyzed in five randomly selected fields. No significant differences were observed between the BSA control group and the blank control group; therefore, BSA was no longer used as a control.

PC12 cells were plated in 96-well plates at the density of $5 \times 10^{5} / \mathrm{ml}$. The cell groupings and treatments were the same as for the aforementioned microscopy assay, and the activity of cells was determined using the MTT method, according the aforementioned protocol.

Determining the expression of neuroinflammatory cytokines and MIF mRNA using the RT-qPCR assay. PC12 cells were plated in 12 -well plates at the density of $5 \times 10^{5} / \mathrm{ml}$. Cells were divided into four groups and exposed to the aforementioned treatments. After treatment, total RNA was extracted and RT-qPCR was conducted using the primers presented in Table I, according the aforementioned protocol.

Kyoto Encyclopedia of Genes and Genomes (KEGG) database search for AGEs signal transduction pathways. KEGG (www.kegg.jp) is a database resource that integrates genomic, chemical and systemic functional information (25). By searching for AGEs-associated signaling pathways, map04933 was identified; AGEs-mediated proinflammatory signaling was investigated using this map.

Statistical analysis. Data are presented as the mean \pm SD. Differences among groups were evaluated using one-way ANOVA followed by Tukey's post hoc test using SPSS version 19.0 software (IBM Corp.) and Prism version 5.0 software (GraphPad Software, Inc.). $\mathrm{P}<0.05$ was considered to indicate a statistically significant difference.

\section{Results}

Effect of AGEs on the expression of MIF $m R N A$ and protein. A significant difference in MIF mRNA expression was not
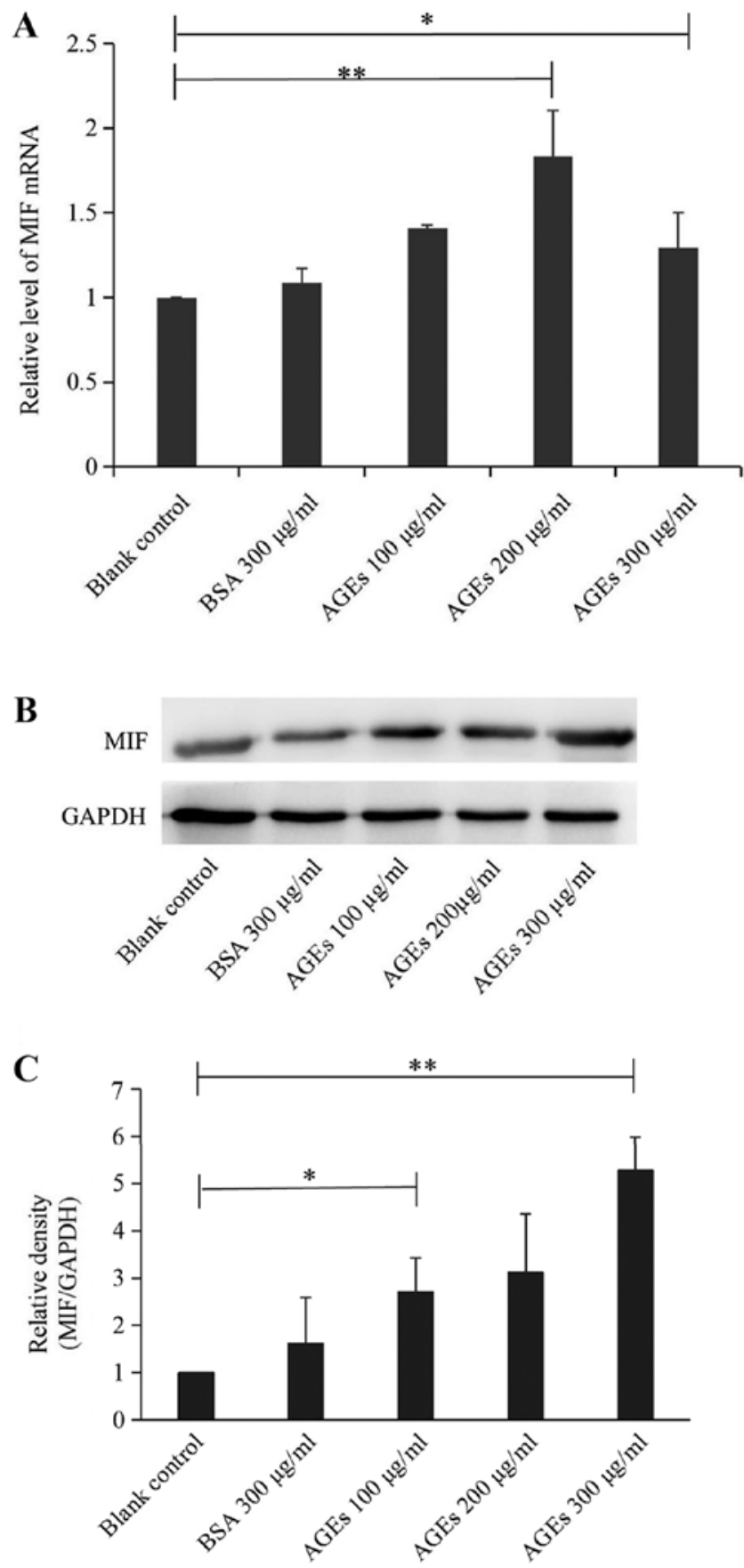

Figure 1. Effects of AGEs on MIF mRNA and protein expression. PC12 cells were treated with different concentrations of AGEs, and the relative expression of MIF (A) mRNA and (B) protein was determined. (C) Quantification of protein expression. The results indicated that AGEs induced MIF expression. Data are presented as the mean \pm SD; $n=3$. ${ }^{*} \mathrm{P}<0.05,{ }^{* *} \mathrm{P}<0.01$. AGEs, advanced glycation end products; MIF, macrophage migration inhibitory factor.

observed between the BSA control group and the blank control group; however, compared with the blank control group, the treatment of cells with 200 or $300 \mu \mathrm{g} / \mathrm{ml}$ AGEs produced statistically significant differences, with MIF mRNA expression significantly increased (Fig. 1A). Cells treated with 100 or $300 \mu \mathrm{g} / \mathrm{ml} \mathrm{AGEs} \mathrm{exhibited} \mathrm{significantly} \mathrm{increased} \mathrm{levels}$ of MIF protein expression compared with the blank control group (Fig. 1B and C). It was hypothesized that a direct intermolecular relationship existed between AGEs and MIF, and 
that AGEs could induce the expression of MIF mRNA and protein.

Optimal concentration of AGEs and the viability of PC-12 cells following treatment with $A \beta_{1-40}$. To screen for the optimum concentration of AGEs, PC12 cells were treated with different concentrations of AGEs, and the survival rate was determined using a CCK- 8 assay. The results revealed that the viability of cells decreased with increasing concentrations of AGEs. The half-maximal effective concentration was calculated to be $335.0 \mu \mathrm{g} / \mathrm{ml}$ using GraphPad Prism 5 software (Fig. 2A). The BSA control group was administered an equivalent concentration of BSA to the optimal concentration of AGEs for PC12 cells $(300 \mu \mathrm{g} / \mathrm{ml})$; no significant difference was observed between the BSA control group and the blank control group (data not shown). The inhibition rate of cells was measured using an MTT assay. As presented in Fig. 2B, the time at which each concentration of $A \beta_{1-40}$ inhibited cell survival to the greatest extent was 12-24 h; however, at $24 \mathrm{~h}$, the cells were poorly adherent and a small number of cells were detached. Therefore, cells were treated with $A \beta_{1-40}$ for $12 \mathrm{~h}$. Using GraphPad Prism 5 software, it was calculated that the half-maximal inhibitory concentration of PC12 cells induced by $\mathrm{A} \beta_{1-40}$ was $22.17 \mu \mathrm{g} / \mathrm{ml}$ (Fig. 2C). The optimal concentration of $A \beta_{1-40}$ treatment and exposure time to establish an AD model was determined to be $20 \mu \mathrm{g} / \mathrm{ml}$ for $12 \mathrm{~h}$.

Cell morphology and activity. Under an inverted microscope (magnification $\mathrm{x} 100$ ), PC12 cells in the blank control group displayed numerous long dendrites. The blank control cells adhered tightly to the bottom of the culture plate, with dense, clear and visible nucleoli, and exhibited a rapid rate of proliferation (Fig. 3A). Compared with the blank control group, the proliferation of cells in the $A \beta_{1-40}$ model group was inhibited, as determined by the decreased number of cells, relaxed intercellular junctions and partial retraction of dendrites (Fig. 3B). Following AGEs treatment, cell proliferation was further inhibited, a large number of cells were detached and more cell fragments were observed; the remaining adherent cells lost their characteristic neuronal features (Fig. 3C). Following pre-treatment with ISO-1, the decrease in cell proliferation was notably attenuated. The number of adherent cells increased, the number of detached cells decreased, cells were strongly adherent, and formed more intercellular junctions with longer and more numerous dendrites (Fig. 3D). Compared with the blank control group, the viability of cells in the $A \beta_{1-40}$ model group significantly decreased; the addition of AGEs further decreased cell viability. Following pre-treatment with ISO-1, the survival rate was significantly improved compared with AGEs and $\mathrm{A} \beta_{1-40}$ alone (Fig. 4). Based on these results, $A \beta_{1-40}$ successfully established an AD cell model. AGEs were found to aggravate the cytotoxicity of $A \beta_{1-40}$ in the AD cell model and this effect was significantly alleviated by exposure to the MIF inhibitor ISO-1.

Expression of neuroinflammatory cytokines and MIF. Compared with the blank control group, the expression levels of interleukin (IL)-1 $\beta$, IL-6, tumor necrosis factor- $\alpha$ $(\mathrm{TNF}-\alpha)$ and MIF mRNA in cells were significantly increased following treatment with $A \beta_{1-40}$. The effects of $A \beta_{1-40}$ on MIF expression were markedly smaller compared with the effects on IL expression; it is possible that other factors in the AD cell
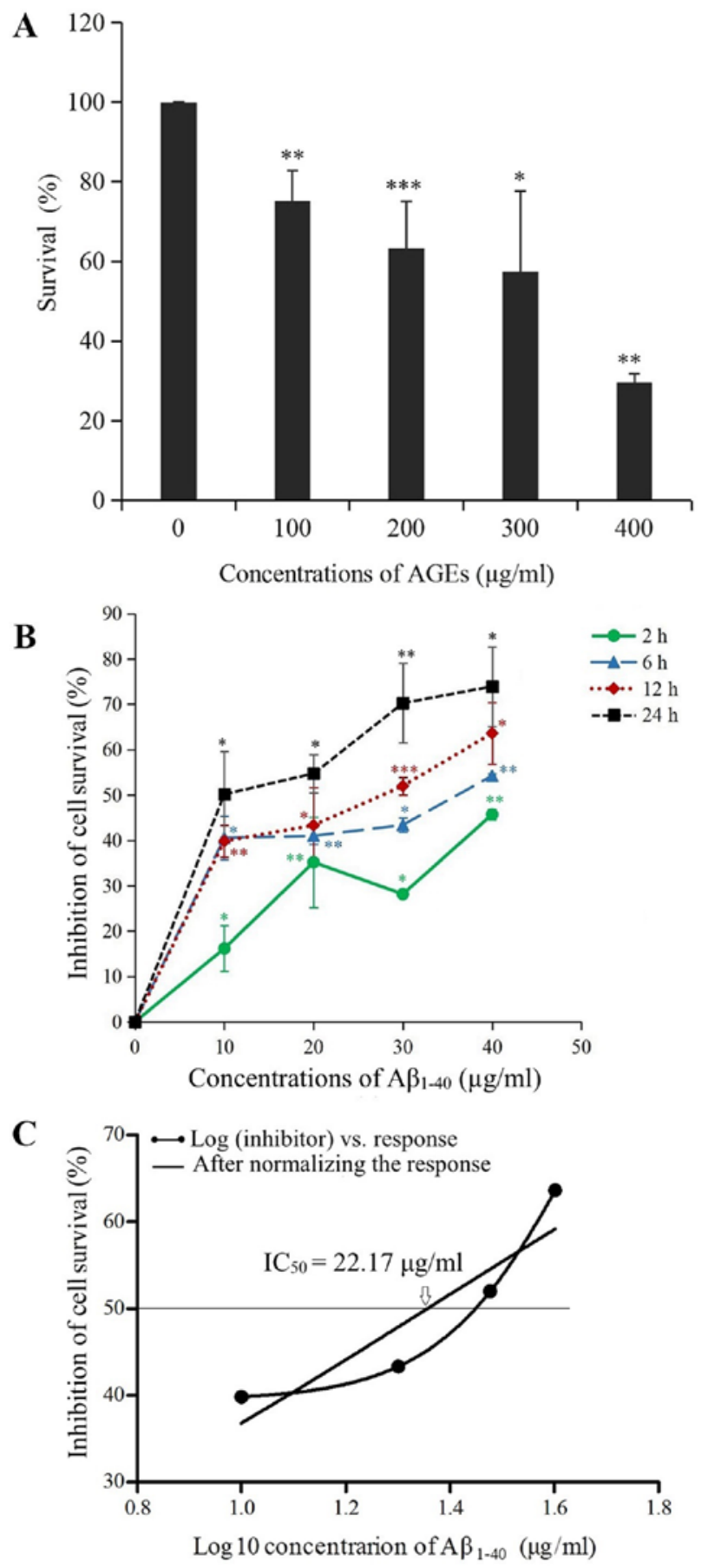

Figure 2. Finding the optimal concentration of AGEs and determining the inhibition of PC12 cell survival induced by $\mathrm{A} \beta_{1-40}$. (A) PC12 cells were treated with different concentrations of AGEs, and the percentage of surviving cells was determined using a Cell Counting Kit- 8 assay; the percentage of surviving cells decreased as the AGE concentration increased. The half-maximal effective concentration was calculated to be $335.0 \mu \mathrm{g} / \mathrm{ml}$ using GraphPad Prism 5 software; therefore, the optimal concentration of AGEs for PC12 cell treatment was determined to be $300 \mu \mathrm{g} / \mathrm{ml}$. (B) PC12 cells were treated with different concentrations of $\mathrm{A} \beta_{1-40}$ for various periods of time. The percent inhibition of cell growth was measured using an MTT assay to determine the most appropriate interval and concentration to create a cell model of AD. Compared with $\mathrm{A} \beta_{1-40}(0 \mu \mathrm{g} / \mathrm{ml})$, the growth of a greater percentage of cells was inhibited as the $A \beta_{1-40}$ concentration increased. (C) Using GraphPad Prism 5 software, it was calculated that the $\mathrm{IC}_{50}$ of $\mathrm{A} \beta_{1-40}$ in $\mathrm{PC} 12$ cells was $22.17 \mu \mathrm{g} / \mathrm{ml}$. The optimal concentration and exposure time of $A \beta_{1-40}$ to establish the AD model was determined to be $20 \mu \mathrm{g} / \mathrm{ml}$ for $12 \mathrm{~h}$. Data are presented as the mean $\pm \mathrm{SD} ; \mathrm{n}=3 .{ }^{*} \mathrm{P}<0.05$, ${ }^{* *} \mathrm{P}<0.01,{ }^{* * *} \mathrm{P}<0.001$ vs. $0 \mu \mathrm{g} / \mathrm{ml}$ AGEs $/ \mathrm{A} \beta_{1-40}$. AGEs, advanced glycation end products; $\mathrm{A} \beta_{1-40}$, amyloid $\beta$ 1-40; $\mathrm{IC}_{50}$, half-maximal inhibitory concentration; AD, Alzheimer's disease. 
A

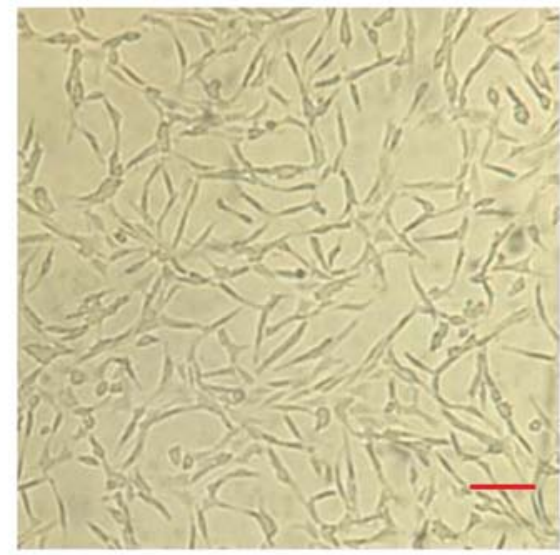

Blank control

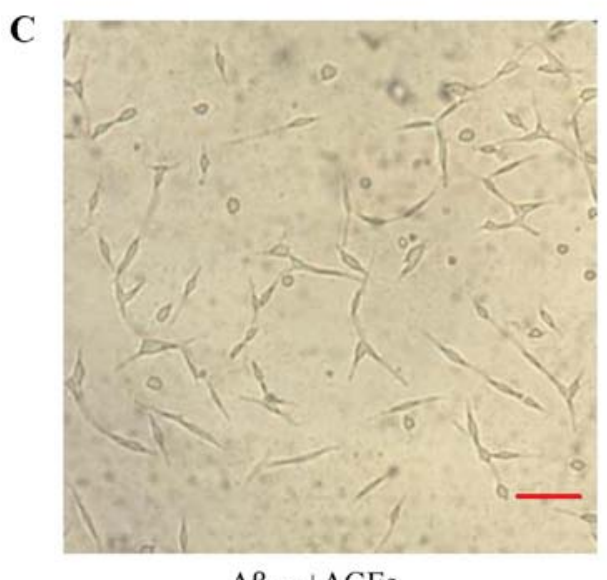

B

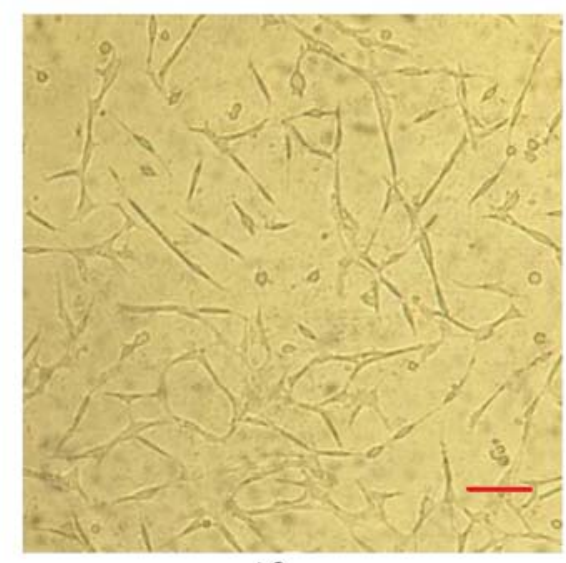

$\mathrm{A} \beta_{1-40}$

D

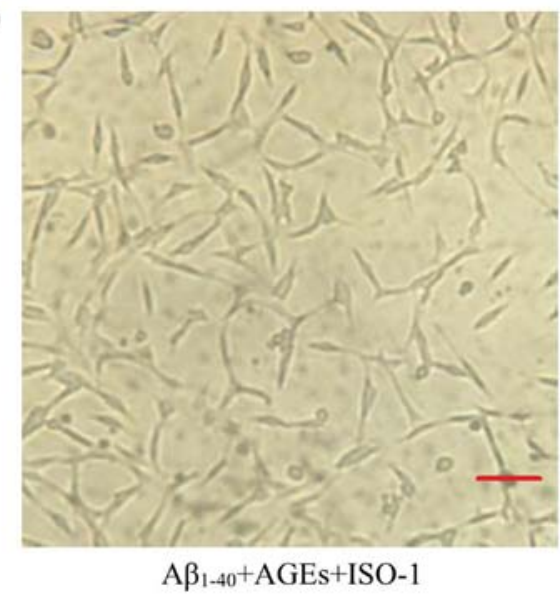

Figure 3. AGEs promote apoptosis by inducing MIF expression. Changes to the number and morphology of cells in the (A) blank group, (B) AD cell model group, (C) AGEs-treated AD model group and (D) ISO-1-pretreated group were observed under an inverted microscope (magnification, x100). AGEs inhibited the proliferation of cells in the AD model; following pre-treatment with the MIF inhibitor ISO-1, the decrease in cell proliferation was notably attenuated Scale bar, $100 \mu \mathrm{m}$. AGEs, advanced glycation end products; $\mathrm{A} \beta_{1-40}$, amyloid $\beta 1-40 ; \mathrm{AD}$, Alzheimer's disease; MIF, macrophage migration inhibitory factor; ISO-1, (S,R)-3-(4-hydroxyphenyl)-4,5-dihydro-5-isoxazole acetic acid methyl ester.

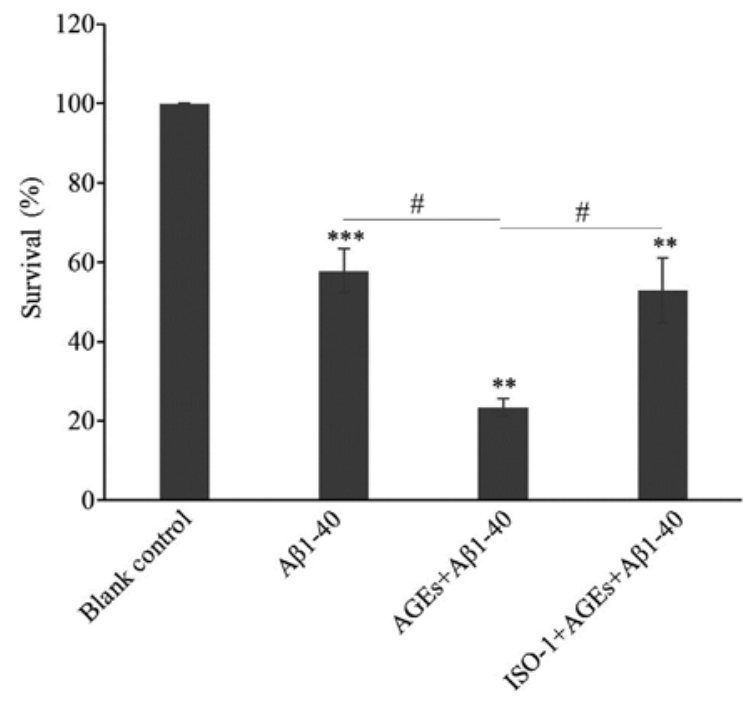

Figure 4. AGEs decrease cell activity by inducing MIF expression. Cell viability in the blank group, AD cell model group, AGEs-treated AD model group and the ISO-1-pretreated group was detected using an MTT assay. ISO-1 attenuated the AGEs-mediated decrease in cellular viability in the AD cell model. Data are presented as the mean $\pm \mathrm{SD} ; \mathrm{n}=3$. ${ }^{* *} \mathrm{P}<0.01,{ }^{* * * *} \mathrm{P}<0.001$ vs. Blank control; ${ }^{\#} \mathrm{P}<0.05$. AGEs, advanced glycation end products; $\mathrm{A} \beta_{1-40}$, amyloid $\beta$ 1-40; $\mathrm{AD}$, Alzheimer's disease; ISO-1, (S,R)-3-(4-hydroxyphenyl)-4,5-dihydro-5-isoxazole acetic acid methyl ester. model may also regulate the expression of MIF. The expression levels of IL-1 $\beta$ and TNF- $\alpha$ were notably further increased by treatment with AGEs, and the expression of MIF and IL-6 was significantly increased. Compared with the group treated with AGEs, pre-treatment of cells with ISO-1 resulted in a significant decrease in the mRNA expression levels of IL-1 $\beta$, IL-6, TNF- $\alpha$ and MIF (Fig. 5). Based on these results, AGEs aggravated neuroinflammation in the AD model by inducing MIF expression, whereas ISO-1 attenuated this damage.

\section{Discussion}

Diabetes has been reported to promote the occurrence of $\mathrm{AD}$ by disrupting the insulin signal transduction pathway. Insulin resistance and T2D may be associated with an increased incidence of AD (6). AGEs, important pathogenic factors involved in DM and its complications, induce neurotoxicity by promoting the deposition of $A \beta$, the hyperphosphorylation of tau protein and the expression of proinflammatory cytokines in glial cells $(14,15)$. MIF inhibits macrophage migration and chemotaxis, and promotes the aggregation of white blood cells at inflammatory sites, serving an important role in a number of diseases, including rheumatoid arthritis, septic shock, inflammatory lung diseases, cancer and delayed-type 

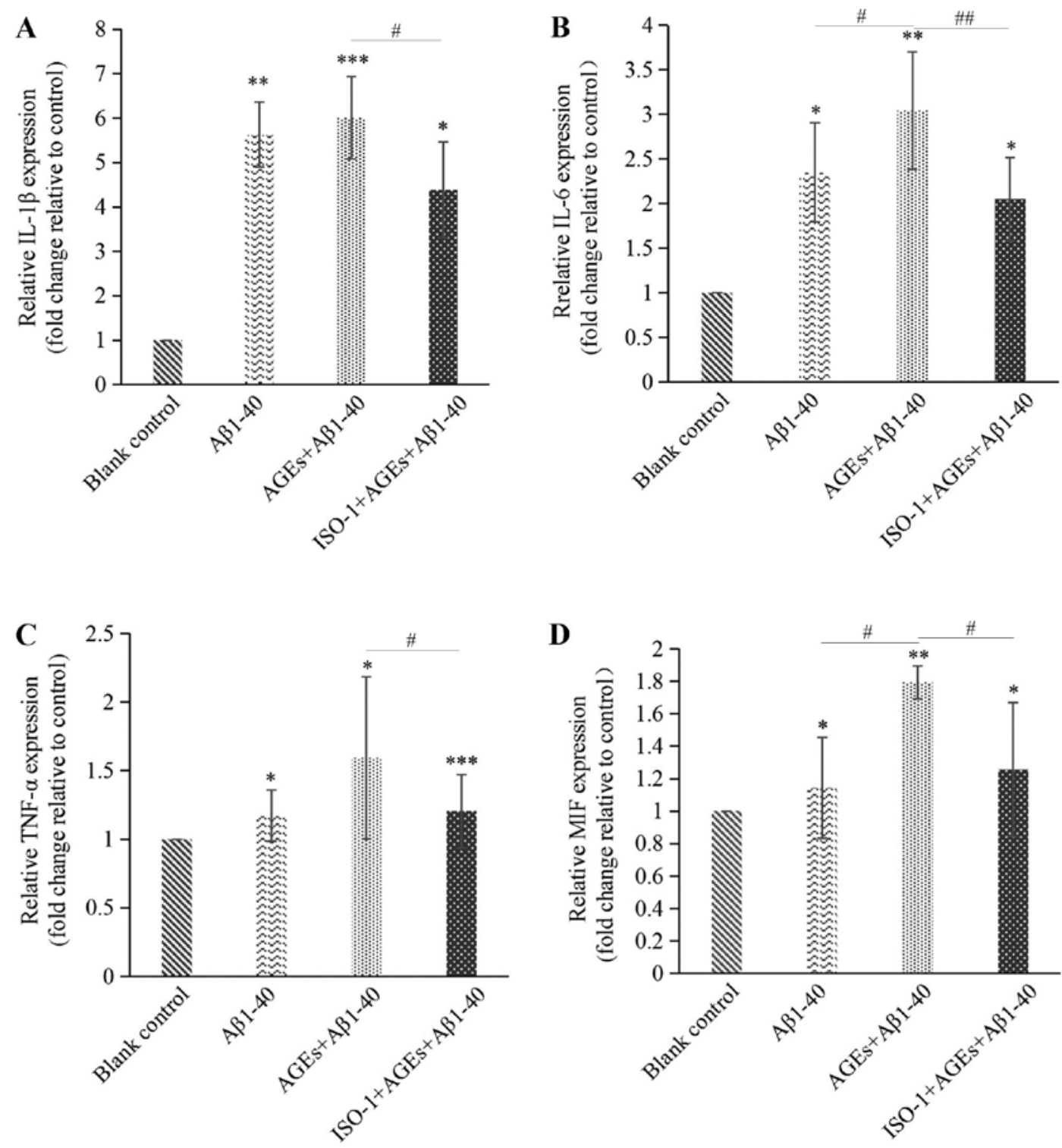

Figure 5. AGEs promote neuroinflammation in the AD cell model by inducing MIF expression. The mRNA expression of (A) IL-1 $\beta$, (B) IL-6, (C) TNF- $\alpha$ and (D) MIF were determined in the blank, AD cell model, AGEs-treated AD model and the ISO-1-pretreated groups via reverse transcription-quantitative PCR. AGEs promoted neuroinflammation in the AD cell model by inducing MIF expression. Data are presented as the mean $\pm \mathrm{SD} ; \mathrm{n}=4$. ${ }^{*} \mathrm{P}<0.05$, ${ }^{* *} \mathrm{P}<0.01,{ }^{* * *} \mathrm{P}<0.001$ vs. Blank control; ${ }^{*} \mathrm{P}<0.05,{ }^{\# *} \mathrm{P}<0.01$. AGEs, advanced glycation end products; $\mathrm{A} \beta_{1-40}$, amyloid $\beta$ 1-40; AD, Alzheimer's disease; ISO-1, (S,R)-3-(4-hydroxyphenyl)-4,5-dihydro-5-isoxazole acetic acid methyl ester; IL, interleukin; TNF- $\alpha$, tumor necrosis factor- $\alpha$.

hypersensitivity (16). MIF promotes the development of diabetes by disrupting the mechanism that regulates the production of inflammatory cytokines, causing insulin resistance and inflammatory injury to islet cells (26). In the present study, the association between AGEs and MIF, and its effects on neuroinflammation in AD, was investigated. AGEs induced the expression of MIF mRNA and protein in PC12 cells, and further aggravated the occurrence of neuroinflammation in the AD cell model. The results showed that the effects of AGEs on the expression of MIF mRNA and protein were not in parallel; the maximal expression of MIF mRNA was observed following treatment with $200 \mu \mathrm{g} / \mathrm{ml}$ AGEs, whereas the expression of MIF protein further increased following treatment with $300 \mu \mathrm{g} / \mathrm{ml}$ AGEs. This phenomenon of non-parallel expression requires further investigation.

AD is a neurodegenerative disease. Hippocampal neuronal injury is an important component of $\mathrm{AD}$ pathology and is closely related to the occurrence of neuritis, the deposition of $\mathrm{A} \beta$ and the hyperphosphorylation of tau proteins (27). A previous study into the causal relationship between neuroinflammation and AD reported that neuroinflammation may be involved in the pathogenesis of $\mathrm{AD}$, and that an increase in the levels neuroinflammatory mediators was observed in AD (28). Thus, neuroinflammation serves an important role in the development of AD. Inflammatory mediators cause cognitive impairment through cytokine-mediated glial cell activation and neuronal toxicity (29). In addition, AD has been associated with the upregulation of proinflammatory cytokines, which promote neuronal degeneration (30). These cytokines include IL-1 $\beta$, IL- 6 and TNF- $\alpha$, which are regarded as important mediators of neuroinflammation and leukocyte infiltration (31). Notable roles of these cytokines include the promotion of $A \beta$ deposition and activation of glial cells (32). In the present study, cells were pre-treated with the MIF inhibitor 
ISO-1 to determine if the increased expression of IL-1 $\beta$, IL-6 and TNF- $\alpha$ was a result of AGE-induced MIF expression. Cells in each group were observed under an inverted microscope, and the effects of a MIF inhibitor on the expression of mRNAs encoding inflammatory mediators were analyzed. AGEs were revealed to mediate neuroinflammation in the AD cell model by inducing MIF expression. MIF inhibitors block the hyperactivation of microglia, and exert anti-inflammatory and neuroprotective effects (33). It was observed that ISO-1 protected the AD cell model from AGEs-mediated damage. The results of the present study may have important theoretical and practical significance in understanding the pathogenesis and prevention of neuroinflammation in $\mathrm{AD}$, and improving treatment.

Previous studies have shown that MIF promotes the development of AD by activating glial cells, initiating cascade reactions, and promoting the occurrence of neuroinflammation, and the formation of senile plaques and NFTs $(19-21,33)$. In the present study, it was demonstrated that AGEs promoted the expression of MIF and aggravated the neuroinflammatory response at the cell level. Future studies should investigate the significance of AGEs in animal models and at the clinical level. Whether AGEs promote MIF expression in glial cells, not only in nerve cells, should also be addressed in future studies using animal models. It should also be investigated as to whether AGEs induce the activation of glial cells by promoting MIF expression, and if AGEs then aggregate around nerve cells, leading to neuroinflammation and the toxic effects of neuronal phagocytosis.

In the present study of the interaction between AGEs and MIF, the molecular signaling pathways affected by AGEs were not discussed in detail. The KEGG database (map04933) revealed that AGEs promoted inflammation via a number of signalling pathways, including the $\mathrm{NF}-\kappa \mathrm{B}$ and PI3K pathways (map not shown). The signaling pathways induced by AGEs that promote the expression of MIF will be investigated in subsequent studies. Novel ideas and methods for the treatment of AD may be discovered with a more complete understanding of the molecular mechanisms underlying AD.

\section{Acknowledgements}

The authors would like to thank Professor Yu Ming (Department of Neurology, Affiliated Hospital of Jiangsu University; Jiangsu University) for providing comprehensive guidance and suggestions on the present study, and the Central Laboratory of The Affiliated Hospital of Jiangsu University for providing a good environment for experiments and high-quality experimental instruments. The authors would also like to thank Dr Shu Yang (Central Laboratory of The Affiliated Hospital of Jiangsu University), for providing technical assistance and support during the present study.

\section{Funding}

The present study was supported by the National Natural Science Foundation of China (grant no. 81871343), and The Jiangsu Provincial Key Research and Development Plan (grant nos. BE2017699 and BE2017698).

\section{Availability of data and materials}

The datasets used and/or analyzed during the current study are available from the corresponding author on reasonable request.

\section{Authors' contributions}

MY and DZ conceived and designed the study, and drafted the manuscript. DZ conducted the experimental protocols and analyzed the experimental results. YX, JM and SQ contributed to the analysis of data and revised the manuscript critically. All authors read and approved the final manuscript.

\section{Ethics approval and consent to participate}

Not applicable.

\section{Patient consent for publication}

Not applicable.

\section{Competing interests}

The authors declare that they have no competing interests.

\section{References}

1. Alzheimer's Association: 2017 Alzheimer's disease facts and figures. Alzheimer's Dementia 13: 325-373, 2017.

2. Mushtaq G, Khan JA, Kumosani TA and Kamal MA: Alzheimer's disease and type 2 diabetes via chronic inflammatory mechanisms. Saudi J Biol Sci 22: 4-13, 2015.

3. Prince M, Bryce R, Albanese E, Wimo A, Ribeiro W and Ferri CP: The global prevalence of dementia: A systematic review and meta analysis. Alzheimers Dement 9: 63-75, 2013.

4. Rawlings AM, Sharrett AR, Schneider AL, Coresh J, Albert M, Couper D, Griswold M, Gottesman RF, Wagenknecht LE, Windham BG and Selvin E: Diabetes in midlife and cognitive change over 20 years: A cohort study. Ann Intern Med 161: 785-793, 2014.

5. Ohara T, Doi Y, Ninomiya T, Hirakawa Y, Hata J, Iwaki T, Kanba S and Kiyohara Y: Glucose tolerance status and risk of dementia in the community: The hisayama study. Neurology 77: 1126-1134, 2011.

6. Kandimalla R, Thirumala V and Reddy PH: Is Alzheimer's disease a type 3 diabetes? A critical appraisal. Biochim Biophys Acta Mol Basis Dis 1863: 1078-1089, 2017.

7. de la Monte SM and Wands JR: Alzheimer's disease is type 3 diabetes-evidence reviewed. J Diabetes Sci Technol 2: 1101-1113, 2008.

8. Steen E, Terry BM, Rivera EJ, Cannon JL, Neely TR, Tavares R, $\mathrm{Xu} \mathrm{XJ}$, Wands JR and de la Monte SM: Impaired insulin and insulin-like growth factor expression and signaling mechanisms in Alzheimer's disease-is this type 3 diabetes? J Alzheimers Dis 7: 63-80, 2005.

9. Rivera EJ, Goldin A, Fulmer N, Tavares R, Wands JR and de la Monte SM: Insulin and insulin-like growth factor expression and function deteriorate with progressionof Alzheimer's disease: Link to brain reductions in acet ylcholine. J Alzheimers Dis 8: 247-268, 2005.

10. Goh SY and Cooper ME: Clinical review: The role of advanced glycation end products in progression and complications of diabetes. J Clin Endocrinol Metab 93: 1143-1152, 2008.

11. Tanaka K, Yamaguchi T, Kanazawa I and Sugimoto T: Effects of high glucose and advanced glycation end products on the expressions of sclerostin and RANKL as well as apoptosis in osteocyte-like MLO-Y4-A2 cells. Biochem Biophys Res Commun 461: 193-199, 2015. 
12. Chang CC, Chen CY, Chang GD, Chen TH, Chen WL, Wen HC, Huang $\mathrm{C}$ and Chang $\mathrm{CH}$ : Hyperglycemia and advanced glycation end products (AGEs) suppress the differentiation of 3T3-L1 preadipocytes. Oncotarget 8: 55039-55050, 2017.

13. Lin JA, Wu CH, Lu CC, Hsia SM and Yen GC: Glycative stress from advanced glycation end products (AGEs) and dicarbonyls: An emerging biological factor in cancer onset and progression. Mol Nutr Food Res 60: 1850-1864, 2016.

14. Sato T, Shimogaito N, Wu X, Kikuchi S, Yamagishi S and Takeuchi M: Toxic advanced glycation end products (TAGE) theory in Alzheimer's disease. Am J Alzheimers Dis Other Demen 21: 197-208, 2006.

15. Vitek MP, Bhattacharya K, Glendening JM, Stopa E, Vlassara H, Bucala R, Manogue K and Cerami A: Advanced glycation end products contribute to amyloidosis in alzheimer disease. Proc Natl Acad Sci USA 91: 4766-4770, 1994.

16. Lue H, Kleemann R, Calandra T, Roger $\mathrm{T}$ and Bernhagen J: Macrophage migration inhibitory factor (MIF): Mechanisms of action and role in disease. Microbes Infection 4: 449-460, 2002.

17. Grieb G, Merk M, Bernhagen J and Bucala R: Macrophage migration inhibitory factor(MIF): A promising biomarker. Drug News Perspect 23: 257-264, 2010.

18. Abed Y, Dabideen D, Aljabari B, Valster A, Messmer D, Ochani M, Tanovic M, Ochani K, Bacher M, Nicoletti F, et al: ISO-1 binding to the tautomerase activesite of MIF inhibits its pro-inflammatory activity and increases survival in severe sepsis. J Biol Chem 280: 36541-36544, 2005.

19. Vujicic M, Senerovic L, Nikolic I, Saksida T, Stosic-Grujicic S and Stojanovic I: The critical role of macrophage migration inhibitory factor in insulin activity. Cytokine 69: 39-46, 2014.

20. Bacher M, Deuster O, Aljabari B, Egensperger R, Neff F, Jessen F Popp J, Noelker C, Reese JP, Al-Abed Y and Dode R: The role of macrophage migration inhibitory factor in Alzheimer's disease. Mol Med 16: 116-121, 2010

21. Oyama R, Yamamoto H and Titani K: Glutamine synthetase, hemoglobin alpha-chain, and macrophage migration inhibitory factor binding to amyloid beta-protein: Their identification in rat brain by a novel affinity chromatography and in Alzheimer's disease brain by immunoprecipitation. Biochim Biophys Acta 1479: 91-102, 2000.

22. Li SQ, Yu Y, Han JZ, Wang D, Liu J, Qian F, Fan GH, Bucala R and Ye RD: Deficiency of macrophage migration inhibitory factor attenuates tau hyperphosphorylation in mouse models of Alzheimer's disease. J Neuroinflammation 12: 1-11, 2015.
23. Livak KJ and Schmittgen TD: Analysis of relative gene expression data using real-time quantitative PCR and the 2(-Delta Delta C(T)) method. Methods 25: 402-408, 2001.

24. Luo XD, Xu B, Zhou J and Tian GP: Protective effect of secretory factors of bone marrow mesenchymal stem cells on beta-amyloid 1-40 induced apoptosis in PC12 cells. J Clin Rehabilitat Tissue Eng Res 13: 7937-7941, 2009.

25. Kanehisa M, Furumichi M, Tanabe M, Sato Y and Morishima K KEGG: New perspectives on genomes, pathways, diseases and drugs. Nucleic Acids Res 45: D353-D361, 2017.

26. Benigni F, Atsunmi T, Calandra T, Metz C, Echtenacher B, Peng $\mathrm{T}$ and Bucala R: The proinflammatory mediator macrophage migration inhibitory factor induces glucose cataboilsm in muscle. J Clin Invest 106: 1291-1300, 2000.

27. Blennow K, de Leon MJ and Zetterberg H: Alzheimer's disease. Lancet 368: 387-403, 2006

28. Nagae T, Araki K, Shimoda Y, Sue LI, Beach TG and Konishi Y: Cytokines and cytokine receptors involved in the pathogenesis of Alzheimer's disease. J Clin Cell Immunol 7: 441, 2016.

29. Heneka MT, Carson MJ, EI Khoury J, Landreth GE, Brosseron F, Feinstein DL, Jacobs AH, Wyss-Coray T, Vitorica J, Ransohoff RM, et al: Neuroinflammation in Alzheimer's disease. Lancet Neurol 14: 388-405, 2015.

30. Azizi G and Mirshafiey A: The potential role of proinflammatory and antiinflammatory cytokines in Alzheimer disease pathogenesis. Immunopharmacol Immunotoxicol 34: 881-895, 2012.

31. Azizi G, Navabi SS, Al-Shukaili A, Seyedzadeh MH, Yazdani R and Mirshafiey A: The role of inflammatory mediators in the pathogenesis of Alzheimer's disease. Sultan Qaboos Univ Med J 15: e305-e316, 2015.

32. Azizi G, Khannazer $\mathrm{N}$ and Mirshafiey A: The potential role of chemokines in Alzheimer's disease pathogenesis. Am J Alzheimers Dis Other Demen 29: 415-425, 2014

33. Zhang Y, Gu R, Jia J, Hou T, Zheng LT and Zhen X: Inhibition of macrophage migration inhibitory factor (MIF) tautomerase activity suppresses microglia-mediated inflammatory responses. Clin Exp Pharmacol Physiol 43: 1134-1144, 2016.

This work is licensed under a Creative Commons Attribution-NonCommercial-NoDerivatives 4.0 International (CC BY-NC-ND 4.0) License. 